\title{
EDUCAÇÃO AMBIENTAL NOS CURSOS DE AGRONOMIA DAS UNIVERSIDADES FEDERAIS RURAIS DO BRASIL
}

\author{
Cirdes Nunes MOREIRA ${ }^{\mathrm{i}}$ \\ Monica Lopes Folena ARAÚJO ${ }^{\mathrm{ii}}$
}

\begin{abstract}
RESUMO
Neste trabalho foram analisadas as concepções de Educação Ambiental (EA) presentes nos projetos pedagógicos (PPC) dos cursos de Agronomia das Universidades Federais Rurais da Amazônia (UFRA), do Semiárido (UFERSA), de Pernambuco (UFRPE) e do Rio de Janeiro (UFRRJ). A pesquisa evidenciou três situações distintas entre as instituições estudadas: uma delas com indícios de uma Educação Ambiental conservadora, desvinculada da natureza social, cultural e política; outra privilegiando um viés mais regionalista, com ênfase no desenvolvimento econômico e presença de alguns matizes de sustentabilidade, associados à busca da cidadania e justiça social; e nas outras duas, uma abordagem de Educação Ambiental integral, contextualizada do ponto de vista da complexidade que envolve as questões da sustentabilidade, inclusive da sua natureza social, cultural e política, uma delas apontando ainda a necessidade de contínua avaliação e reformulação da formação acadêmica do agrônomo, a qual demanda completa revisão dos currículos, favorecendo a atuação profissional crítica que considere os aspectos políticos, econômicos, sociais, ambientais e culturais, com visão ética e humanística.
\end{abstract}

PALAVRAS-CHAVE: Educação ambiental; Agronomia; Currículo; Universidades federais rurais.

\section{ENVIRONMENTAL EDUCATION IN THE AGRONOMY COURSES OF THE RURAL FEDERAL UNIVERSITIES OF BRAZIL}

\begin{abstract}
In this work, the concepts of Environmental Education (EA) present in the pedagogical projects (PPC) of the Agricultural Course of Federal Universities of Amazon (UFRA), of Semiarid (UFERSA), of Pernambuco (UFRPE) and Rio de Janeiro (UFRRJ). The research evidenced three distinct situations among the studied institutions: one with indications of a conservative Environmental Education, disconnected from the social, cultural and political nature; another focusing on a more regionalist bias, with an emphasis on economic development and the presence of some sustainability shadings associated with the pursuit of citizenship and justice; and in the other two, a comprehensive Environmental Education approach, contextualized from the point of view of complexity that involves sustainability

\footnotetext{
${ }^{\text {i }}$ Doutorando em Ensino de Ciências e Matemática (PPGEC) da Universidade Federal Rural de Pernambuco (UFRPE), Mestre em Extensão Rural e Desenvolvimento Local, Engenheiro Agrônomo do Departamento de Educação (DEd), Membro do Grupo de Pesquisa em Formação e Prática Pedagógica de Professores de Ciências e Biologia (FORBIO) e da Cátedra Paulo Freire da UFRPE. E-mail: cirdesnm@ gmail.com.

ii Doutora em Educação, Professora do Departamento de Educação (DEd) e do Programa de Pós-Graduação em Ensino de Ciências (PPGEC) da Universidade Federal Rural de Pernambuco (UFRPE), Líder do Grupo de Pesquisa em Formação e Prática Pedagógica de Professores de Ciências e Biologia (FORBIO), Coordenadora da Cátedra Paulo Freire da UFRPE. E-mail: monica.folena@gmail.com.
} 
issues, including their social, cultural and political nature, one of them also pointing to the need for continuous evaluation and reformulation of academic training of the agronomist, who demands a complete revision of the curricula, favoring critical professional work that considers the political, economic, social, environmental and cultural aspects, with an ethical and humanistic vision.

KEYWORDS: Environmental education; Agronomy; Curriculum; Federal rural universities.

\title{
LA EDUCACIÓN AMBIENTAL EN LOS CURSOS DE AGRONOMÍA DE LAS UNIVERSIDADES FEDERALES RURALES DE BRASIL
}

\begin{abstract}
RESUMEN
En este trabajo se analizaron las concepciones de Educación Ambiental (EA) presentes en los proyectos pedagógicos (PPC) de los Cursos de Agronomía de las Universidades Federales Rurales de la Amazonia (UFRA), del Semiárido (UFERSA), de Pernambuco (UFRPE) y de Río de Janeiro (UFRRJ). La investigación evidenció tres situaciones distintas entre las instituciones estudiadas: una de ellas con indicios de una Educación Ambiental conservadora, desvinculada de la naturaleza social, cultural y política; otra privilegiando un sesgo más regionalista, con énfasis en el desarrollo económico y presencia de algunos matices de sostenibilidad, asociados a la búsqueda de la ciudadanía y la justicia; y en las otras dos, un enfoque de Educación Ambiental integral, contextualizada desde el punto de vista de la complejidad que involucra las cuestiones de la sostenibilidad, incluso de su naturaleza social, cultural y política, una de ellas apuntando a la necesidad de una continua evaluación y reformulación de la formación académica del agrónomo, la cual demanda completa revisión de los currículos, favoreciendo la actuación profesional crítica que considere los aspectos políticos, económicos, sociales, ambientales y culturales, con visión ética y humanística.
\end{abstract}

PALABRAS CLAVE: Educación ambiental; Agronomía; Plan de estudios; Universidades federales rurales.

\section{INTRODUÇÃO}

A base de dados oficiais do Ministério da Educação (MEC) aponta a existência de 340 cursos de agronomia em funcionamento no país, atualmente oferecidos em todos os estados da federação, em instituições predominantemente públicas. Segundo dados do Conselho Federal de Engenharia e Agronomia (CONFEA), até o ano de 2014, contabilizava-se um total de quase 90 mil engenheiros agrônomos formados pelas diferentes instituições (GLOBO RURAL, 2014).

O campo de interesse do presente estudo são as quatro universidades federais rurais do país, assim denominadas por serem aquelas que foram estruturadas inicialmente para a área de Ciências Agrárias, quais sejam: a Universidade Federal Rural da Amazônia (UFRA), localizada em Belém, no estado do Pará; a Universidade Federal Rural do Semiárido (UFERSA), situada 
em Mossoró, no Rio Grande do Norte; a Universidade Federal Rural de Pernambuco (UFRPE), sediada em Recife; e a Universidade Federal Rural do Rio de Janeiro (UFRRJ), localizada no município de Seropédica.

Com este estudo, que teve como motivação a oportunidade de penetrar em um ambiente profissional ainda pouco explorado - a formação acadêmica dos agrônomos, conforme ressalta Silveira-Filho (2010) -, buscou-se identificar as concepções de Educação Ambiental (EA) presentes nos projetos pedagógicos (PPC) do curso de Agronomia destas instituições, analisando que indícios tais documentos trazem de valorização da EA enquanto ação educativa interdisciplinar, articuladora de um conjunto de saberes, que vise contribuir para a formação de atitudes e sensibilidades ambientais que privilegiem uma visão complexa de meio ambiente, onde a natureza integra uma rede de relações não apenas naturais, mas também sociais e culturais. Tais competências são fundamentais para o bom exercício profissional da agronomia, conforme é requerido atualmente pela sociedade.

\section{A EDUCAÇÃO AMBIENTAL NA FORMAÇÃO DOS AGRÔNOMOS}

Nas atividades dos agrônomos junto aos diferentes atores no campo, a formação universitária e as concepções sobre EA parecem influenciar as abordagens e práticas desses profissionais, sobretudo junto àqueles segmentos mais fragilizados, que teriam ocupado lugar não privilegiado no contexto dos currículos, tecnologias, políticas públicas e processos produtivos, muitas vezes direcionados à lógica do agronegócio, fortalecida a partir da segunda metade do século XX pela modernização da agricultura, conforme salientam Souza (2006) e Grings (2009), entre outros autores. Esta, influenciando os currículos e os processos tecnológicos, privilegiou o viés tecnicista, a fragmentação do conhecimento e a tendência à visão simplificada diante da complexidade que envolve os problemas e suas soluções, cujos alcances se processaram em níveis desiguais em relação às regiões e aos diferentes grupos sociais no campo.

Diante de tais amplitudes, as questões ambientais, que têm sido alvo de reflexões e debates no cenário mundial, também guardam estreita relação com as atividades dos agrônomos, considerando o impacto das suas intervenções sobre a natureza que tem o homem como uma de suas partes. Assim, convém ao agrônomo salvaguardar a cidadania, os projetos sociais emancipatórios e transformadores, a perspectiva da construção de uma sociedade 
ecologicamente prudente, socialmente justa, culturalmente diversa, politicamente atuante e economicamente viável. Estes são alguns dos aspectos levantados por Layrargues, ao prefaciar a obra de Loureiro (2012), que devem assumir lugar privilegiado nessas intervenções.

Diversos autores vêm analisando a EA na formação dos agrônomos. Souza (2006), em sua dissertação apresentada ao Mestrado em Educação da Universidade Federal de Santa Maria (UFSM), analisou o cenário de elaboração do PPC do curso de Agronomia daquela universidade, no que tange às possibilidades e dificuldades de inserção da EA. Já Grings (2009), em sua tese defendida no Doutorado em Educação da Universidade Federal do Rio Grande do Sul (UFRGS), investigou o espaço formal e os significados atribuídos à EA em políticas públicas e nos cursos de graduação em Engenharia Agronômica na UFRGS e UFSM. Mais recentemente, Araújo e Oliveira (2015) também desenvolveram estudos sobre a EA no curso de Agronomia na Universidade Federal de Sergipe (UFS).

Em sua tese de doutoramento sobre o projeto formativo no curso de Agronomia da Universidade Federal do Ceará (UFC), Silveira-Filho (2010) analisou como esse projeto possibilita a profissionalidade necessária para responder aos desafios e às demandas do meio rural. $\mathrm{O}$ autor destacou a tendência da universidade em desenvolver a EA sob forte influência dos métodos tradicionais e positivistas, nos quais a razão e a objetividade "não sintonizam com uma proposta voltada para uma relação harmônica e integrativa entre sociedade e natureza" (SILVEIRA-FILHO, 2010, p. 89).

Desde o ano de 1972, com a realização da I Conferência Internacional sobre Meio Ambiente, em Estocolmo, a EA vem se tornando objeto de políticas públicas no Brasil e no mundo. A institucionalização no âmbito federal, em 1973, com a criação da Secretaria Especial do Meio Ambiente (SEMA); a Constituição Federal de 1988, que estabelece a qualidade ambiental como direito e dever de todos; e a Política Nacional de Meio Ambiente (PNMA), de 1981, que tornou necessária a inclusão da EA em todos os níveis de ensino, são marcos importantes na trajetória que teve a EA, instituída no Brasil pela Lei 9.795, de 27 de abril de 1999 (BRASIL, 1999). Entretanto, vale salientar que no Plano Nacional de Educação (PNE) 2014-2024 deu-se um retrocesso em relação à EA, pois esta está ausente (SILVA; COUTINHO, 2014).

Da forma como está definida na PNMA, a EA deve ser desenvolvida como uma prática educativa integrada, contínua, permanente, transversal e interdisciplinar, e não como disciplina 
específica incluída nos currículos escolares. Trata-se de um componente essencial e permanente da educação no país, que deve estar presente, de forma articulada em todos os níveis e modalidades do processo educativo, seja ele de caráter formal, seja não formal (BRASIL, 1999).

Layrargues (2004) chama atenção que o termo "Educação Ambiental" abrange diferentes classificações e denominações que explicitam e preenchem de sentido as práticas e reflexões pedagógicas relacionadas às questões ambientais. Araújo (2012a) também destaca a pertinência a respeito do entendimento das diferentes tipologias que garantem o reconhecimento das identidades da EA que vêm despontando no Brasil e no mundo. Assim, na análise das concepções de EA, essas podem ser sistematizadas conforme seus diferentes tipos em: conservadora, crítica, transformadora, ecopedagogia, alfabetização ecológica - delimitados em Layrargues (2004) - e ainda, crítico-humanizadora, conforme os estudos realizados por Araújo (2012b).

O estudo do PPC pode oferecer revelações a respeito de um curso, da instituição ofertante e das intencionalidades na sua concepção. Dessa maneira, Araújo (2012b) encontrou indícios importantes para os resultados alcançados pela pesquisa que realizou sobre o quefazer da Educação Ambiental crítico-humanizadora na formação de professores de Biologia, ao analisar o Plano de Desenvolvimento Institucional (PDI) e o Plano Político Pedagógico Institucional (PPPI) da UFRPE e da Universidade Federal de Pernambuco (UFPE).

O caráter político que permeia os PPC, nos quais gravitam interesses e forças, finda por delimitar pedagogicamente as ações educativas para que os cursos cumpram seus propósitos e intencionalidades. Nesse sentido, a EA integrada, contínua, permanente, transversal e interdisciplinar tem se tornado um direcionamento estratégico. Sua perspectiva transformadora valoriza a formação cidadã, entretanto ela está quase ausente nos currículos tradicionais, de abordagem conservadora e fragmentada, também na formação dos agrônomos que, na maioria dos casos, privilegia o tecnicismo, conforme salientam Souza (2006) e Grings (2009).

Ao analisar questões referentes ao currículo e à formação profissional na educação superior, Pithan e Fensterseifer (2008) chamam atenção para o necessário desafio de sairmos da perspectiva eminentemente epistemológica e técnica e assumirmos um olhar político sobre a formação profissional, missão que incluirá além dos cientistas, educadores e especialistas, a sociedade de uma maneira geral. De acordo os referidos autores: 


\begin{abstract}
A preocupação deixa de ser exclusivamente epistemológica e técnica para ser eminentemente política, sendo tarefa e desafio não apenas dos cientistas, educadores e especialistas, mas de toda a sociedade em geral. Aos institutos de ensino superior cabe compreender esta problemática redefinindo sua "política de formação profissional" no sentido de propiciar uma "formação humanística" voltada ao "desenvolvimento sustentável" (PITHAN; FENSTERSEIFER, 2008, p. 3).
\end{abstract}

Esta missão e este olhar vêm assumindo lugar de destaque também entre os autores que se debruçam sobre as questões inerentes à formação dos engenheiros agrônomos, sobretudo no que tange ao necessário esforço de inserção da EA nos currículos das instituições formadoras no país, pela compreensão que a EA proporciona, com a perspectiva crítica de abordagem que pode trazer, os vieses político, humanístico e do desenvolvimento sustentável, tão importantes e necessários para a formação desses profissionais.

\title{
3 METODOLOGIA
}

O presente trabalho, de cunho qualitativo, consistiu em uma análise documental. Para Oliveira (2007, p. 69), a pesquisa documental “[...] caracteriza-se pela busca de informações em documentos que não receberam nenhum tratamento científico, como relatórios, revistas, cartas, filmes [...]”. Nesse sentido, compreendemos que os PPC são documentos desta natureza.

A análise dos documentos foi feita seguindo-se princípios da Análise de Conteúdo, logo, efetivou-se em três fases: pré-análise; exploração do material; e, tratamento dos resultados, inferência e interpretação (BARDIN, 1994), com vistas a inferir quais concepções de Educação Ambiental permeiam os PPC dos cursos de Agronomia da UFRA, da UFERSA, da UFRPE e da UFRRJ, instituições cujas características gerais são descritas a seguir.

Universidade Federal Rural da Amazônia: A UFRA foi institucionalizada em 2002. O curso de Agronomia iniciou suas atividades em 1951, pela antiga Escola de Agronomia da Amazônia (EAA), antecessora da Faculdade de Ciências Agrárias do Pará (FCAP), hoje transformada em UFRA, que é a mais antiga Instituição de Ensino Superior e de Pesquisa Científica e Tecnológica na área de Ciências Agrárias da região. O curso de Agronomia é oferecido atualmente nos municípios paraenses de Belém, Capanema, Capitão Poço e Paragominas. O PPC analisado (UFRA, 2009), composto de 53 páginas, foi publicado no ano de 2009.

Universidade Federal Rural do Semiárido: Oriunda da Escola Superior de Agricultura de Mossoró (ESAM), criada em 1967, a UFERSA foi institucionalizada em 2005. 
Além do município de Mossoró, sua área de influência atinge todos os municípios da microrregião salineira e também as áreas de grandes projetos de irrigação, tais como: BaixoAssú e Chapada do Apodi, no Rio Grande do Norte; e Baixo Banabuiú, Médio-Jaguaribe e Região do Cariri, no Ceará. O PPC analisado (UFERSA, 2006) tem 66 páginas e foi publicado no ano de 2006.

Universidade Federal Rural de Pernambuco: O curso de Agronomia da UFRPE é oferecido desde o ano de 1914 no campus sede, em Recife - PE e, a partir da recente política de expansão universitária para os municípios do interior do estado, é ofertado também nas unidades acadêmicas em Garanhuns (distante 230km de Recife) desde 2005, e em Serra Talhada (distante $413 \mathrm{~km}$ do Recife) desde 2006. O período desta expansão coincide com a conclusão, em 2006, do PPC analisado (UFRPE, 2006), que tem 94 páginas e abrange as três unidades acadêmicas.

Universidade Federal Rural do Rio de Janeiro: O curso de Agronomia da UFRRJ teve seu início com a inauguração da Escola Superior de Agronomia e Medicina Veterinária, em 1913, e formou sua primeira turma em 1916. Ao longo da sua existência, formou milhares de profissionais e influenciou a criação de diversas escolas de Agronomia. De acordo com informações disponíveis no endereço eletrônico da instituição, atualmente ingressam 75 estudantes por semestre, estando efetivamente matriculados 650 alunos. O PPC analisado (UFRRJ, 2009) consta de 29 páginas e não traz as ementas das disciplinas oferecidas, embora essas estejam disponíveis na internet (http://cursos.ufrrj.br/grad/agronomia/ementas/).

Optamos neste trabalho por preservar a identidade das instituições analisadas, tratandoas a partir daqui por "universidade A", "universidade B", "universidade C" e "universidade D", sequência que, logicamente, não guarda correspondência com a ordem em que as instituições se encontram citadas na descrição anterior ou nas demais partes deste texto.

Durante as leituras dos PPC, foram destacados fragmentos dos textos que deram origem as 191 unidades de registro para a análise realizada. Segundo Bardin (1994, p.130), unidade de registro "é a unidade de significação a codificar e corresponde ao segmento de conteúdo a considerar como unidade de base, visando à categorização e análise frequencial”. Trataram-se, conforme Bardin estabelece, de unidades de natureza e dimensões muito variáveis, analisadas em nível semântico no presente estudo. 
As unidades de registro foram codificadas visando seu agrupamento em categorias, possibilitando a compreensão da significação das unidades de registro, contextualizando-as para que se pudesse finalmente inferir os sentidos que elas expressam e, no seu conjunto, quais as ideias centrais dos documentos analisados, que pudessem responder à questão que norteia o problema desta pesquisa, ou seja: Quais concepções de EA estão presentes nos PPC dos cursos de Agronomia das Universidades Federais Rurais do Brasil?

Considerando os referenciais teóricos que envolvem a Educação Ambiental e a formação dos agrônomos, o agrupamento por similaridade semântica das unidades de registro resultou na formação de três categorias: concepção de Educação Ambiental (EA), concepção sobre o PPC (P), e Perfil do egresso (E); e treze subcategorias: enfoque conservador de EA (c), ênfase no agronegócio (a), abordagem utilitarista (u), abordagem tecnicista (t), abordagem interdisciplinar (i), abordagem ecológica, de meio-ambiente, de sustentabilidade (emas), abordagem regionalista (r), abordagem de sociedade (s), PPC anterior (v), PPC atual (n), Universidade "A" (ua), Universidade "B" (ub), Universidade "C" (uc) e Universidade "D" (ud).

As subcategorias codificadas como " $v$ " e " $n$ " indicam se a unidade de registro trata do PPC anterior " $v$ ", ou do atual " $n$ ", respectivamente, tendo em vista que na apresentação dos PPC existem menções ao projeto anterior, geralmente para explicar as razões que motivaram a concepção de um novo PPC, já que pelo menos um dos projetos analisados trata-se de uma reformulação do anterior vigente.

As demais subcategorias dizem respeito aos sentidos presentes nas unidades de registro. Cabe registrar que elas podem trazer mais de um sentido, situações nas quais lhes são atribuídos mais de um código. Nestes casos, a ordem de codificação procurou ser fiel à ordem dos sentidos presentes em cada unidade, do mais enfático para o menos enfático.

Para a análise realizada, foram seguidas as regras definidas por Bardin (1994), em relação à exaustividade (leitura e releitura dos dados por diversas vezes), pertinência, exclusividade e representatividade. O processo de análise foi construído sempre buscando estabelecer relações entre o referencial teórico e os núcleos de sentidos emergentes, a partir das leituras dos PPC.

A cada unidade de registro foi atribuído um número, de 1 a 191 (em itálico), o que permite na análise perceber, por exemplo, que "165P.v.uc" diz respeito à unidade de registro de número 165, que trata sobre característica do PPC "P", anterior "v", da Universidade C "uc": 
"A grande justificativa para a reformulação curricular do atual Curso de Agronomia prendese ao fato de ainda prevalecer no seu conteúdo programático a rigidez de um Currículo Mínimo”.

\section{RESULTADOS E DISCUSSÃO}

A expressão "Educação Ambiental" é citada apenas no PPC da Universidade "A", no contexto de um único componente curricular, denominado "Técnicas em Educação Ambiental" (51 horas/aula). Nos demais PPC a expressão não é citada. A existência do referido componente curricular, como espaço exclusivo para tratar de questões ambientais, entretanto, não se coaduna com o que define a PNMA, segundo a qual a EA deve ser desenvolvida como uma prática educativa integrada, contínua, permanente, transversal e interdisciplinar, mas não como disciplina específica incluída nos currículos escolares (BRASIL, 1999).

Por outro lado, quanto à ausência da expressão "Educação Ambiental”, cumpre ponderar sobre o risco que pode significar o entendimento de que "as questões referentes à Educação se acham suficientemente esclarecidas", conforme alertam Rodrigues (2001) apud Cavalari, Santana e Carvalho (2006, p. 144),

Ao intencionalizar sua prática, ou seja, ao dar uma significação conceitual e valorativa para sua ação, o educador o faz a partir de determinadas ideias, crenças, valores, ideologias, conhecimentos e saberes, vale dizer, a partir de determinadas concepções. A intencionalização da prática pedagógica se realiza, portanto, a partir de concepções. Tais concepções, no entanto, nem sempre se expressam de maneira clara e transparente.

Assim, compreendendo que as concepções de EA nem sempre poderiam estar suficientemente explicitadas, buscamos valorizar nesta análise as concepções de EA implícitas, a partir dos elementos ou indícios evidenciados nos documentos.

\subsection{Universidade "A"}

A análise do PPC da universidade "A" revelou uma abordagem de EA integral, contextualizada do ponto de vista da complexidade que envolve as questões da sustentabilidade, inclusive do ponto de vista da sua natureza social, cultural e política.

A sustentabilidade é tratada em diferentes momentos, frequentemente associada à perspectiva de aproximação com a sociedade, valorizando o desenvolvimento e 
compartilhamento dos conhecimentos de natureza técnica, científica e cultural, conforme delimitado na missão institucional de

[...] contribuir para o desenvolvimento sustentável da [região], através da formação de profissionais de nível superior, desenvolvendo e compartilhando conhecimentos técnico, científico e cultural, e oferecendo serviços à comunidade por meio do ensino, pesquisa e extensão (4E.s.ua, p. 8).

A ênfase nos processos de gestão participativa fica fortemente evidenciada no PPC, no qual há indicações de valorização dessas práticas vivenciadas junto às comunidades acompanhadas, mas também dentro do funcionamento da instituição, inclusive no que concerne à concepção das estruturas curriculares.

A [ua] avançou em suas conquistas durante seu processo de transformação de tal maneira, que tem atualmente, em cumprimento ao que exige a legislação, estatuto, regimento geral e plano estratégico, concebidos a partir de processos democráticos e participativos, registrando na história desta Universidade, um avanço na área de gestão participativa (8P.s.ua, p. 9).

A delimitação dos objetivos do curso evidencia a importância do compromisso com o homem e o ambiente regional, também quando trata das exigências e inserção no mercado. Aspectos como a visão integral e humanística são destacados no texto, revelando uma abordagem diferenciada em relação à ênfase tecnicista que se sobressai em grande parte dos currículos nos cursos de Agronomia no país, conforme destacam Souza (2006) e Grings (2009). No PPC, encontramos que é compromisso da Universidade:

Formar engenheiros agrônomos com capacidade técnico-científica e visão integral, ética e humanística, comprometidos com o bem-estar da sociedade envolvida, exercendo todas as competências relacionadas à profissão e a promoção do desenvolvimento sustentável (20E.EA.s.emas.ua, p. 16).

As perspectivas de criticidade, ética e abordagem holística na utilização dos fatores que compõem os sistemas de produção, incorporando ainda a aptidão para educar, nos processos de planejamento, pesquisa e solução de problemas, são características que qualificam o perfil dos profissionais formados pela universidade "A", destacadas no PPC analisado, que denota fortes indícios de uma abordagem interdisciplinar presente no processo formativo.

O profissional formado no Curso de Agronomia [...] será capaz de atuar nas áreas de competência do Engenheiro Agrônomo, estabelecidas pela legislação profissional vigente de forma crítica e ética, com capacidade técnico-científica e responsabilidade social. Aptos a promover, orientar e administrar de forma holística a utilização e otimização dos diversos fatores que compõem os 
sistemas de produção, em consonância com os preceitos de proteção ambiental. Aptos a educar, planejar, pesquisar e aplicar técnicas, métodos e processos adequados à solução de problemas e à promoção do desenvolvimento rural sustentável (25E.EA.s.emas.ua, p. 17).

\subsection{Universidade " $B$ "}

O PPC de Agronomia da universidade "B" evidencia um processo formativo fortemente calcado na perspectiva regional, partindo do enaltecimento de algumas características da economia e potencialidades da região onde a instituição está inserida e da importância do curso como elemento que traz contribuições nessa direção.

Este fato permite a [ub] tornar-se uma instituição universitária voltada aos segmentos de pesquisa, ensino e extensão com o objetivo de despertar vocações alternativas e competitivas ao potencializar as vantagens edafoclimáticas da região e gerar soluções para impulsionar com sustentabilidade econômica, social e ambiental os diversos modelos de produção agropecuária da região (52EA.r.emas.u.ub, p. 8).

Com uma filosofia de formação apoiada na ética, cooperação, cidadania e justiça social, o PPC define como objetivo para o curso formar "homens e mulheres com iniciativa, alto padrão moral e ético, responsáveis, produtivos, cooperativos, cidadãos, ecológicos, felizes e agentes da felicidade das comunidades que dependerão dos seus ensinamentos" (88E.s.ub, p. 25-26). Com isso, a instituição revela no documento princípios importantes para o processo formativo, com indícios de prática de EA transformadora: “a [ub] coloca-se a serviço do progresso e das aspirações da coletividade, segundo os princípios de liberdade e respeito aos direitos individuais e valores humanos, tendo por base a prudência ecológica, a eficiência econômica e a justiça social" (53EA.s.emas.ub, p. 8).

Fortalecendo este direcionamento, o perfil profissiográfico delineado destaca a natureza político-ideológica, para além da científica, como característica dos egressos da instituição (79P.s.ub, p. 23), cujo diferencial do processo de ensino-aprendizagem "é justamente o fato de que sua base não é só tecnológica ou econômica, mas também ambiental, social, cultural e política" (78EA.s.emas.ub, p. 23).

O PPC apresenta uma análise crítica à lógica produtivista na formação dos agrônomos, cujo modo de pensar e agir trouxe uma série de consequências danosas, tais como empobrecimento das populações e desastres ecológicos. Diante disto, o PPC enfatiza a 
necessidade de um contexto educativo que busque minimizar os problemas ocasionados pela formação tecnicista e fragmentada dos agrônomos. Encontramos no PPC:

A segunda característica, ditada pelo modelo desenvolvimentista adotado no país, reflete-se na formação do agrônomo via incorporação/difusão do discurso e da prática produtivista; este, consistindo em pressupor que a melhoria da produtividade agrícola produz melhoria na renda e esta por sua vez melhora as condições de vida e trabalho das populações do campo. Esse modo de pensar e agir trouxe como consequência forte concentração de renda e terra, processo acentuado de empobrecimento das populações rurais, desastres ecológicos, entre outros efeitos catastróficos para a economia tradicional, para o tecido social, para o desenvolvimento cultural e para a preservação dos ecossistemas locais (81EA.s.emas.ub, p. 23-24).

[...] um contexto educativo que venha a contribuir para minimizar os efeitos de um processo de formação baseado nas características acima comentadas, um projeto político-pedagógico consistente com o interesse da maioria sociedade, deve evitar: a marginalização da ciência do homem, da sociedade, da educação e do meio ambiente (82P.s.emas.ub, p. 24).

Os elementos apontados no PPC trazem fortes indícios de uma EA transformadora presente no processo formativo. $\mathrm{O}$ direcionamento do curso para a perspectiva de agricultura moderna enfatizada na região onde a instituição está inserida parece estar associado aos valores importantes da sustentabilidade, viabilizada pela vida social justa, digna e cidadã. Nesse sentido, destacamos o seguinte trecho do PPC:

Economia e Ecologia de mãos dadas, pois se temos consciência do compromisso com as gerações atuais, sabemos que é nossa responsabilidade histórica, deixarmos para as futuras gerações um planeta sadio, autossustentável, capaz de viabilizar economicamente uma vida social justa, digna e cidadã (77E.s.emas.ub, p. 23).

Vale salientar que, embora encontremos no texto supramencionado indícios da valorização de práticas educativas com EA, Ecologia nem sempre está associada ao trabalho efetivo com EA. Segundo estudos de Araújo (2012a, 2012b), a Ecologia trata de aspectos como ecossistemas, nicho ecológico, relações ecológicas e outros, mas isso não implica que, necessariamente, a EA será trabalhada atrelada à Ecologia.

\subsection{Universidade "C"}

A parte inicial do PPC delimita a integração dos diversos departamentos acadêmicos envolvidos com o curso, na promoção das adaptações que se fizerem necessárias, inclusive com processos de avaliação periódica junto aos docentes, discentes e outros fóruns. 
A implementação desse Projeto e as devidas adaptações que se fizerem necessárias ao longo do tempo, haverá de contar com a efetiva integração dos diversos Departamentos Acadêmicos responsáveis, direta ou indiretamente, pelo Curso de Agronomia (106P.n.i.uc, p. 9).

Aqui cumpre destacar que a equipe que elaborou o PPC, conforme consta no documento, contou apenas com representação do campus sede da universidade, não havendo nenhuma referência que trate de adequações da proposta em relação às outras unidades acadêmicas institucionais onde o curso é oferecido.

Tal fragilidade se acentua considerando que o enfoque regional não é apresentado com grande visibilidade no PPC analisado, aparecendo em apenas cinco unidades de registro, uma na parte que trata de características gerais do PPC (107E.s.emas.r.uc) e as demais sendo mencionadas nas apresentações de ementas de alguns componentes curriculares do ciclo profissionalizante, tais como: Floricultura, Plantas Ornamentais e Paisagismo (127EA.r.t.emas.uc), Fruticultura (128EA.r.uc), Manejo de Solos no Semiárido (129EA.r.emas.uc) e Ciência do Solo (145EA.t.r.uc).

$\mathrm{O}$ atual PPC foi elaborado a partir da crítica ao anterior, cuja estrutura trazia "uma preocupação em fortalecer as áreas de Engenharia e Ciências Humanas" (156P.v.s.uc), que terminou sendo vista como causadora de uma série de problemas, tais como: longa duração do curso, evasão, baixas notas nos exames de avaliação nacional. Os trechos a seguir revelam este entendimento:

Houve uma preocupação em fortalecer as áreas de Engenharia e Ciências Humanas. Como resultado, o Curso de Agronomia da [uc] passou a ter uma duração mínima de cinco anos e meio e onze períodos letivos, com 4.475 horas, sendo considerado um dos mais longos cursos de Agronomia do País (156P.v.s.uc, p. 6).

Naquela proposta pedagógica, por apresentar um excessivo número de disciplinas, que compartimentalizavam o conhecimento das áreas, levando muitas vezes à repetição de conteúdos de maneira desnecessária, constatou-se a falta de melhor integração entre as disciplinas de formação básica e as do ciclo profissional, tornando o curso demasiadamente longo e desarticulado. (157P.v.uc, p. 7).

É curioso quando se atribuem ao antigo PPC todos os problemas anteriormente listados para justificar a necessidade da sua reformulação, visando ao atendimento das aspirações pessoais dos que se interessam pela profissão, mas também da sociedade brasileira. O PPC reformulado parece não cumprir esse sentido social na sua acepção mais ampla, quando 
privilegia uma abordagem tecnicista, fortemente direcionada ao agronegócio, com notável fragmentação do conhecimento, dedicando apenas 6,4\% da carga horária de Componentes Obrigatórias do Curso (3.375 horas/aula), às cinco disciplinas agrupadas na categoria "Desenvolvimento Rural”, a saber: Princípios de Sociologia Rural (30 horas/aula), Economia Rural (60 horas/aula), Administração e Planejamento Rural (60 horas/aula), Legislação e Política Agrária (45 horas/aula) e Extensão Rural (60 horas/aula) (172P.n.uc, p. 16).

Além disto, dentre os componentes optativos não existe, no PPC analisado, a disponibilidade de nenhuma disciplina na categoria "Desenvolvimento Rural", nem mesmo na categoria "Meio Ambiente", que aparece neste conjunto de categorias criadas na proposta, igualmente sem nenhuma disciplina ali agrupada como possibilidade para os alunos cursarem caso quisessem se aprofundar um pouco mais nessas abordagens.

Os achados deste estudo coincidem com o realizado por Grings (2009), no âmbito da UFRGS e UFSM, que revelou, apesar da crescente preocupação com a EA em nível governamental e a consciência mais aguçada quanto à importância do tema na formação profissional dos agrônomos, ainda ser incipiente o espaço da EA nos PPC dos cursos de Agronomia, que mantêm estruturas curriculares tradicionais, mesmo a despeito do esforço de alguns professores na inserção da EA nos PPC, nas estruturas curriculares, nas práticas educativas e nos seus processos de formação continuada, feitas de forma contextualizada e comprometida com a sociedade.

Carvalho (2006, p. 163), tratando sobre educação e cidadania, também destaca a importância de uma educação crítica que forneça elementos para a formação de sujeitos capazes de se posicionar em torno das questões ambientais:

Do ponto de vista de sua dimensão político-pedagógica, a EA poderia ser definida, lato sensu, como uma educação crítica voltada para a cidadania. Uma cidadania expandida, que inclui como objeto de direitos a integridade dos bens naturais não renováveis, o caráter público e a igualdade na gestão daqueles bens naturais dos quais depende a existência humana. Neste sentido, uma EA crítica deveria fornecer os elementos para a formação de um sujeito capaz tanto de identificar a dimensão conflituosa das relações sociais que se expressam em torno da questão ambiental quanto de posicionar-se diante desta (CARVALHO, 2006, p.163).

Pois bem, o PPC analisado evidencia que a valorização da perspectiva cidadã presente no projeto que o antecedeu, tão logo completou seu primeiro ciclo de formação, deu lugar a novas discussões, já no início dos anos 2000, apoiando-se, para tanto, em diversas críticas ao 
currículo implementado, tais como: a rigidez de um currículo mínimo e a duração mínima de cinco anos e meio, dentre outras, tendo como resultante que o curso estaria caracterizado pela "existência de uma arcaica grade curricular, rígida e de longa duração" (158P.v.uc, p. 7).

A análise realizada possibilitou perceber que as abordagens vinculadas aos aspectos sociais no PPC estão circunscritas à parte inicial do documento, a qual representa $1 / 4$ do seu conteúdo. Dessa maneira, o perfil do egresso, por exemplo, delimita que a proposta "visa principalmente consolidar o perfil do Engenheiro Agrônomo egresso como apto a participar na sociedade civil, sendo ator proativo do desenvolvimento do segmento agrário na atual conjuntura da nação brasileira" (105E.s.uc, p. 9), contemplando o graduando com uma “formação generalista para sua participação social na história da sociedade civil, com a prática equilibrada da cidadania e de seu exercício profissional conforme as exigências e avanços da sociedade civil organizada e do mercado de trabalho" (108E.s.uc, p.10).

Assim, na sua parte mais geral, em que pesem as ressalvas feitas ao PPC anterior, cujo viés mais humanista teria resultado na série de problemas já relatados e que motivaram a concepção de uma nova proposta curricular, o PPC analisado estabelece como finalidade para o curso, o desenvolvimento de conhecimentos e processos que guardem relação com o equilíbrio ambiental, considerando as perspectivas regionais, e ainda os aspectos de natureza histórica e social. Dentre os objetivos específicos do curso, o primeiro deles é:

Desenvolver conhecimentos científicos para o estabelecimento de tecnologias socialmente justas, para o desenvolvimento de processos produtivos que imitem ou respeitem o equilíbrio dos ecossistemas naturais do País, mais particularmente [da região]. Propor modificações e/ou transformações nos sistemas de produção [regionais], a partir do conhecimento dos ecossistemas, e do entendimento da formação histórica e das características atuais, no que tange à posse e uso da terra, às relações de trabalho e à base técnica (107E.s.emas.r.uc, p. 10).

Por outro lado, além do que é tratado na parte inicial do PPC, referente às perspectivas sociais e políticas que devem ser levadas em conta nos processos de EA, na apresentação das ementas dos componentes curriculares estas abordagens são encontradas exclusivamente nos componentes obrigatórios da área de Ciências Humanas. As ementas de todos os demais componentes se restringem a abordagens teóricas ou práticas, fragmentadas, que não dialogam entre si, com forte viés tecnicista e ênfase no agronegócio, conforme apresentado a seguir: 
O Brasil é atualmente o terceiro maior exportador mundial de produtos agrícolas e agora compete no mercado global com Estados Unidos, União Europeia e Austrália. No ano passado, o agronegócio respondeu por 30\% do Produto Interno Bruto (PIB) brasileiro, gerando 37\% dos empregos nacionais e representando $40 \%$ de todas suas exportações (119E.a.uc, p. 13).

Reforçando o entendimento da supremacia das questões de natureza técnica sobre aquelas de natureza social na abordagem de ambiente, já na delimitação do objetivo geral do curso, no PPC, as questões de natureza técnica precedem as de natureza social e política e, nesse sentido, convém lembrar que Bardin (1994) evidencia a pertinência de considerar a ordem de aparição das unidades de registro nas entrevistas ou relatos, conferindo significado de maior importância no quadro de inferências para aqueles elementos que precedam outros (BARDIN, 1994, p. 138).

O Curso de Agronomia da [uc] tem como objetivo ministrar o ensino das Ciências Agrárias em nível superior, graduando Engenheiros Agrônomos capazes de promover, orientar e administrar a utilização dos fatores de produção visando racionalizar a produção vegetal e animal, planejar, pesquisar e aplicar técnicas, métodos e processos adequados à solução de problemas agrícolas e pastoris. Considerando genericamente também os aspectos sócio-econômicos, políticos, culturais e éticos, mas sempre visando o desenvolvimento agrário sustentável e preenchendo os requisitos previstos no Decreto n. 23.196, de 12/12/1933, a Lei n. 5.194, datada de 24/12/1966, e a Resolução CONFEA n. 218, de 29/06/1973, que juntas regem o exercício legal da profissão do Engenheiro Agrônomo no Brasil (170P.n.t.s.uc, p. 10, grifo nosso).

A análise do PPC possibilitou inferir a emergência de fortes indícios de uma concepção de EA conservadora, "naturalizada" que, conforme define Carvalho (2006, p. 35), tende a ver a natureza como o "mundo da ordem biológica", essencialmente boa, equilibrada, estável, autônoma e independente da interação com o mundo cultural humano, personificada em algumas passagens unicamente no próprio agrônomo, cuja presença aparece como a "chave" para a solução ou geração dos problemas.

\subsection{Universidade " $D$ "}

Em relação à Universidade "D", a análise do PPC revelou que o projeto foi concebido a partir de reflexões críticas sobre as limitações da formação agronômica tradicional, destacando a necessidade de que essa formação precisa transcender a perspectiva meramente econômica que foi fortalecida com a elevada tecnificação da produção agropecuária, vivenciada no Brasil durante a segunda metade do século XX, no processo denominado modernização da 
agricultura. Assim, a partir do PPC proposto, a universidade "D" se propõe a oferecer uma formação que acompanhe as mudanças e os avanços da sociedade valorizando a necessidade do desenvolvimento sustentável.

Desta maneira, o PPC do curso traz um chamamento à atuação crítica, que considere os aspectos políticos, econômicos, sociais, ambientais e culturais.

[...] observando tanto o aspecto do progresso social quanto da competência científica e tecnológica, permitirá ao profissional a atuação crítica na identificação e resolução de problemas, considerando seus aspectos políticos, econômicos, sociais, ambientais e culturais, com visão ética e humanística, em atendimento às demandas da sociedade (180P.n.E.s., p. 12).

É sempre muito forte no PPC da Universidade " $D$ ” o sentido de assegurar uma formação de agrônomos que sejam aptos a compreender e traduzir as necessidades dos indivíduos, grupos sociais e comunidade, em relação aos problemas tecnológicos, socioeconômicos, gerenciais e organizacionais, "bem como a utilizar racionalmente os recursos disponíveis, além de conservar o equilíbrio do ambiente" (181E.EA.s.emas.ud, p. 12). Nesse sentido, a promoção da perspectiva interdisciplinar e transdisciplinar, como forma de superar a criticada fragmentação entre os saberes e contribuir para a construção de saberes voltados para os valores e relações humanas, são aspectos importantes do ponto de vista de condicionar um cenário que favoreça a EA crítica no processo de formação profissional.

Disciplinas optativas presentes na estrutura curricular, tais como: Sociedade e Agricultura no Brasil (60 horas/aula); Ideologia do Moderno no Campo (60 horas/aula); Políticas e Projetos de Desenvolvimento Rural e a Agricultura Familiar (60 horas/aula); Agricultura Familiar e Sustentabilidade (60 horas/aula); Política e Economia de Recursos Naturais e Conflitos Agroambientais (30 horas/aula); História Agroambiental Brasileira e Latino-americana (30 horas/aula); Política e Relações de Poder no Campo (60 horas/aula), dentre outras, indicam a valorização dessas temáticas na estrutura curricular e que favorecem a EA crítica no processo formativo ali vivenciado.

\section{CONSIDERAÇÕES FINAIS}

A pesquisa realizada evidenciou situações distintas entre os PPC analisados: a universidade "C" apresentou no PPC fortes indícios de uma Educação Ambiental conservadora, desvinculada da natureza social, cultural e política; a universidade "B" revelou um viés mais 
regionalista, com ênfase no desenvolvimento econômico e presença de alguns matizes de sustentabilidade, associados à busca da cidadania e justiça social; já as universidades "A" e "D" evidenciaram uma abordagem de EA integral, contextualizada do ponto de vista da complexidade que envolve as questões da sustentabilidade, inclusive do ponto de vista da sua natureza social, cultural e política.

Tal fato elucida que os cursos de Agronomia formam profissionais com perfis distintos em relação à EA e, nesse sentido, há a necessidade de se repensar a inserção da dimensão ambiental nas matrizes curriculares. Afinal, faz toda a diferença um agrônomo que atue norteado por princípios da sustentabilidade ambiental, tais como respeito à natureza e valorização das questões relacionadas à cidadania. Um profissional com esse perfil poderá contribuir de forma efetiva para encontrarmos modos mais sustentáveis para plantar, irrigar, combater pragas e conservar o solo, por exemplo, além de ser capaz de influir para a emancipação e organização das pessoas envolvidas com os processos de produção no meio rural, levando em conta as gerações futuras.

Os resultados apontados nesta pesquisa referem-se, apenas, à análise dos PPC dos cursos. Mas destacamos que a dimensão ambiental pode estar presente em documentos oficiais e não se materializar na prática docente dos professores formadores. E, por outro lado, a dimensão ambiental pode estar pouco presente, presente de modo conservador ou até ausente de documentos que regem a universidade e o curso, mas estar presente na prática docente, aspecto importante de ser considerado para se ter maior clareza a respeito das concepções de EA que estão permeando a formação dos Engenheiros Agrônomos diplomados nestas instituições. Nesse sentido, ressaltamos a importância de os documentos orientadores institucionais apontarem um perfil de agrônomo sensibilizado à manutenção da vida em todas as suas formas, norteando assim a oferta de disciplinas no curso. Desta maneira, torna-se igualmente relevante que os professores formadores, bem como os estudantes e gestores dos cursos conheçam tais documentos para que, por sua vez, estejam todos atentos em pautar o perfil do egresso que reflita tais avanços.

\section{REFERÊNCIAS}

ARAÚJO, Juliana Barreto Silva; OLIVEIRA, Paula Ellen Silva. A educação ambiental na grade curricular do curso de Agronomia da UFS. Revista Sergipana de Educação

Ambiental. São Cristóvão - SE, v. 11, n. 2, p. 112-129, 2015. Disponível em: http://www.seer.ufs.br/index.php/revisea/article/view/4447. Acesso em: 20 nov. 2015. 
ARAÚJO, Monica Lopes Folena. A Educação ambiental no mundo e no Brasil: sementes plantadas. In: OLIVEIRA, G. (org.). Formando Educadores Socioambientais. Recife: Núcleo de Estudos em Formação Docente e Prática Pedagógica (NEFOPP), Editora da UFRPE, 2012a. p. 4-20.

ARAÚJO, Monica Lopes Folena. O quefazer da Educação Ambiental críticohumanizadora na formação inicial de professores de Biologia na universidade. Orientadora: Tereza Luiza de França. 2012. Tese (Doutorado em Educação) - Universidade Federal de Pernambuco, Recife, 2012 b.

BARDIN, Laurence. Análise de conteúdo. Lisboa: Edições 70, 1994.

BRASIL. Lei 9.795, de 27 de abril de 1999. Dispõe sobre a Educação Ambiental, institui a Política Nacional de Educação Ambiental e dá outras providências. Disponível em: http://www.planalto.gov.br/ccivil_03/Leis/L9795.htm. Acesso em: 1 nov. 2015.

CARVALHO, Isabel Cristina de Moura. Educação ambiental: a formação do sujeito ecológico. 2. ed. São Paulo: Cortez, 2006.

CAVALARI, Rosa Maria Feiteiro; SANTANA, Luiz Carlos; CARVALHO, Luiz Marcelo. Concepções de educação e educação ambiental nos trabalhos do I EPEA. Pesquisa em Educação Ambiental, v. 1, n. 1, p. 141-173, 2006. Disponível em: http://repositorio.unesp.br/handle/11449/108277. Acesso em: 01 nov. 2015.

GLOBORURAL. Cursos de Engenharia Agronômica no Brasil. Notícias, 23 de setembro de 2014. Disponível em: http://revistagloborural.globo.com/Noticias/noticia/2014/09/listafaculdades-de-engenharia-agronomica.html. Acesso em: 27 mar. 2016.

GRINGS, Venice Teresinha. Educação ambiental no ensino superior: estudo de caso no curso de Agronomia. Orientadora: Merion Campos Bordas. 2009. Tese (Doutorado) Universidade Federal do Rio Grande do Sul, Porto Alegre, 2009.

LAYRARGUES, Philippe Pomier (org.). Identidades da educação ambiental brasileira. Brasília: Ministério do Meio Ambiente, 2004.

LOUREIRO, Carlos Frederico B. Trajetória e fundamentos da educação ambiental. 4. ed. São Paulo: Cortez, 2012.

OLIVEIRA, Maria Marly de. Como fazer pesquisa qualitativa. Petrópolis, RJ: Vozes, 2007.

PITHAN, Sidinei da Silva; FENSTERSEIFER, Paulo Evaldo. Currículo profissional na educação superior. Revista E-Curriculum, v. 4, n. 1, p.1-17, 2008. Disponível em: http://revistas.pucsp.br/index.php/curriculum/article/view/3215/2137. Acesso em: 5 nov. 2018.

SILVA, Daywison Borges da; COUTINHO, Solange Fernandes Soares. Os Planos Nacionais de Educação: encontros e desencontros entre educação e sustentabilidade no âmbito da pesca 
artesanal. In: ABRANCHES, Ana de Fátima P. de Sousa, et al. (org.). Pesquisa educacional e o direito à educação: múltiplas abordagens. Recife: Fundação Joaquim Nabuco, Editora Massangana, 2014. p. 13-28.

SILVEIRA-FILHO, José. O projeto formativo do Engenheiro Agrônomo no curso de Agronomia da UFC em Fortaleza. Orientador: André Haguette. 2010. (Tese de Doutorado) - Universidade Federal do Ceará, Fortaleza, 2010.

SOUZA, Sandra Elisa Réquia. A inserção da Educação Ambiental no Currículo do Curso de Agronomia: um estudo de caso na UFSM. Orientador: Claiton Jose Grabauska. 2006. (Dissertação de Mestrado) - Universidade Federal de Santa Maria, Santa Maria-RS, 2006.

UFERSA. Projeto Político Pedagógico: Curso de Agronomia. Universidade Federal Rural do Semi-Árido, Curso de Agronomia. Mossoró, 2006. Disponível em: https://agronomia.ufersa.edu.br/wp-content/uploads/sites/26/2014/09/AGRONOMIA.pdf. Acesso em: 27 out. 2018.

UFRA. Projeto Político Pedagógico do Curso de Agronomia. Universidade Federal Rural da Amazônia, Curso de Agronomia. Belém, 2009. Disponível em:

https://cca.ufra.edu.br/images/PDF/PPCA_atualizado_30092015.pdf. Acesso em 27 out. 2018.

UFRPE. Projeto Político Pedagógico do Curso de Agronomia. Universidade Federal Rural de Pernambuco, Curso de Agronomia. Recife, 2006. Disponível em:

http://www.ufrpe.br/sites/www.ufrpe.br/files/PROJETO\%20PEDAG\%C3\%93GICO\%20DO \%20CURSO.pdf. Acesso em: 27 out. 2018.

UFRRJ. Curso de Agronomia: Projeto político pedagógico. Universidade Federal Rural do Rio de Janeiro, Curso de Agronomia. Seropédica: Ed. da UFRRJ, 2009.

Enviado em: 12/11/2018

Aprovado em: 07/06/2019 